\title{
The Segmentals of Bilingual Nigerian Adult Broca's Aphasics
}

\author{
Adesina B. Sunday \\ Department of English \\ University of Ibadan \\ Ibadan, Nigeria \\ Tel: +23408062119697 \\ E-mail: sinadaybuk@yahoo.com
}

Received: 18-01-2013

doi:10.7575/aiac.ijalel.v.2n.3p.83
Accepted: 19-03-2013

Published: 01-05-2013

\begin{abstract}
This paper examined the segmental phonology of 25 purposively sampled bilingual Nigerian adult Broca's aphasics from a Nigerian teaching hospital. Data were collected by tape-recording the speech of each of the aphasic. The data were analysed perceptually, complemented with frequency count and simple percentage. The way the subjects ranked constraints were then examined, using Optimality Theory. Three main forms of deviation were noticed in their speech: deletion, substitution and epenthesis, with substitution having the highest frequency, followed by deletion. The deviation affected consonants more than vowels. Plosives and alveolars were more affected by the brain damage than any other sound. Some of the effects of Nigerian English on the speech of the subjects were still retained after the brain damage. The Broca's aphasics sampled ranked constraints in such a way that markedness dominated faithfulness.
\end{abstract}

Keywords: Bilingual Nigerian adult aphasics, Optimality Theory, deviation, substitution, deletion, epenthesis

\section{Introduction}

Much of the research on aphasia from a neurolinguistic perspective has concentrated on mainly first language (L1) speakers of English, little on French, German, and some other European languages [French (Bouhman \& Grumbaum 1925; Lecours \& Lhermitte 1969), German ( Goldstein, 1948), English (Green 1969; Goodglass et al, 1972; Blumstein 1973; Goodglass \& Kaplan,1983), Turkish (Peuser and Fittschen, 1977), Russian (Luria, 1966), and Finnish (Niemi, Korvuselka-Sallimen \& Hanninen, 1985]. Neurolinguistic research on African aphasics, in general, and Nigerian aphasics, in particular, is just emerging.

Nigeria is a multilingual speech community. Over and above the over four hundred Nigerian indigenous languages (Bamgbose, 1971), English enjoys the status of official language. It has acclimatized with and has been flavoured by the various indigenous languages, such that a variety of the Standard British English, called Nigerian English (NE), now exists, with its peculiarities at all levels of linguistic analysis, though it is not yet fully codified.

Few scholars have attempted investigating the language of Nigerian aphasics. One of them is Salami (2005). He investigated the language of a stroke patient. The patient was a 58 -year-old woman who had been hypertensive for 22 years. He claims that her speech was characterized by omission, such as 'range' for orange; substitution, such as 'beat' for meat; addition of some phonemes to some words, like 'ealse' for ease, and distortion of some words, for example 'dest' for diet. In the cases of substitution, the places of articulation were not different but, in some cases, the manners of articulation were different. While examining the speech of a native Yoruba speaker of English suffering from dysarthria owing to tongue lesion, Salami (2008) asserts that the speech of the subject was characterized by hyponasalisation. Other features identified include weak articulation of $/ 1 /$ and $/ \mathrm{r} /$; backing of alveolar stops to velar stops; omission of segments in cluster; and inability to show contrast in words and phonemes.

Also in their examination of an adult female stroke patient diagnosed with expressive aphasia, Salami and Akande (2006) found that, although her speech was grammatically deviant (as she often omitted some grammatical items, like auxiliaries, articles, prepositions and pronouns) contrary to known characteristics of agrammatic patients, she could still use some grammatical items properly. However, she had some problems with using the first person personal pronoun.

The suprasegmentals of bilingual Nigerian adult aphasics is the focus of Sunday (2010). With Optimality Theory as the theoretical framework, he sampled 20 aphasics and found that aphasia did not affect the stress and intonational patterns of the subjects but the rhythm of their speech was affected. To account for the rhythm of their speech, he proposed Syllable-Pause Timing, since none of the existing theories of rhythm could adequately account for their rhythm.

This linguistic situation suggests that Nigerian adult aphasics (who are essentially bilinguals) will exhibit some linguistic peculiarities which may not be observable in aphasics who have English as first language. These peculiarities have significant implications for the therapy and rehabilitation of these patients. A thorough investigation of these peculiarities, most especially at the phonological level, will assist the patients and those who treat them. In view of the current state of research on the linguistic features of Nigerian aphasics, this paper undertook a description of the segmental phonology of bilingual Nigerian adult Broca's aphasics. The intention is to provide language therapists and 
other caregivers data that they can base their assessment and rehabilitation on.

\section{Types of aphasia}

Aphasia could be broadly categorized into two: Broca's and Wernicke's. The other forms are classified in relation to them. Global Aphasia shows features of these two. Conduction Aphasia tends toward Wernicke's. Transcortical Motor Aphasia shows features of Broca's Aphasia, except that there are better repetition abilities in the former. Transcortical Sensory Aphasia is similar to Wernicke's Aphasia although, in it, there is better retention of what is said and repetition is relatively intact; Mixed Transcortical Aphasia is similar to Broca's Aphasia (Whitaker, 1975:38-39; Parker, 1986:208; Wingfield, 1992; Wertz, 1996:48; Edwards, 2002:20; Caplan, 2003:585).

Broca's aphasia is otherwise known as expressive or motor aphasia. The lesion is located in the lower frontal lobe, just anterior to the Rolandic fissure, which divides the frontal and parietal lobes. It is characterized by non-fluent and effortful speech articulation; simplification of consonant clusters; substitution; missing function words and bound morphemes. Broca's aphasics lack the means to appropriately present their ideas although they know what to say (Caplan, 2003:585).

Wernicke's aphasia is also known as receptive aphasia (because it affects linguistic comprehension rather than linguistic output), or sensory aphasia (because the sensory cortex is damaged). The lesion is located in the upper surface of the temporal lobe, affecting the auditory cortex, and occasionally the parietal lobe. It is characterized by fluent spontaneous speech; phonemic paraphasias; verbal paraphasias; neologisms, paragrammatisms; use of general proforms and hackneyed phrases; errors in the use of determiners and pronouns; problems with comprehending the speech of others; problems in retrieving words from memory; and circumlocutions (Parker, 1986: 191; Crystal 1987: 271).

\section{Methodology}

Twenty-five subjects, the youngest of whom was 35 years old, were used for this study. They were Nigerian adult Broca's aphasics (with English and at least one Nigerian indigenous language) got from the University College Hospital, Ibadan, Oyo State, Nigeria. They were sampled at the wards and the Medical Out-Patient (MOP) Clinic of the hospital.

Only those patients with language impairment were sampled. Before interacting with them at all, it was ascertained that they had speech deficits. Those who had almost fully recovered their lost speech ability at the time of data collection were excluded from the research. The tape-recording method was used to document their speeches. The unstructured interview method was used to elicit information from the subjects. In most cases, the patients were asked to narrate the onset of the stroke. Other issues relating to how they felt about their loss of speech were raised in the course of interacting with them.

Consultant neurologists did the clinical diagnosis of the patients. The researcher was granted access to their case files, from which some demographic and relevant clinical data were collected. Other demographic data that could not be got from the case files were supplied by either the patients or their caregivers, upon request. The subjects were given a short passage containing some words representing some of the concepts examined in the study.

The analysis of the speech of the subjects was mainly perceptual. The recorded data were listened to so as to discover the features being investigated. The analysis adopted largely an endonormative approach, assessing the phonology of the subjects based on NE rather than Received Pronunciation (RP). This was done because the analysis of the deviation or impairment is better based on the phonologies that they had already acquired. Some patterns which might be seen as forms of deviation in RP are the norms in NE.

The statistical approach was also adopted for analysis. The instances of deviation noticed in their speech were identified; the frequency of occurrence of each instance of deviation was recorded. The frequencies and percentages of occurrence of the forms of deviation were then compared. After identifying the forms of deviation, Optimality Theory (OT) was used to explicate how some of these instances of deviation, rather than the NE and the RP output candidates, emerged as optimal outputs.

\section{Optimality Theory (OT)}

Optimality Theory (OT) proposes that Universal Grammar (UG) is made up of a set of violable constraints (Oyebade, 1998; Fox, 2002:198; Cartell, 2006:194).These constraints, that is, statements that spell out universal properties of language, are ranked in different ways in each language. Differences between constraints rankings produce different patterns which result in systematic variations among languages (Archangeli, 1997:11).

There are two formal mechanisms that mediate between the input and the output: GEN (Generator) and EVAL (Evaluator). The first creates linguistic objects and notes their faithfulness to the input being considered, while the second makes use of the constraint hierarchy of the language to select the best candidate(s) for a given input among the candidates produced by the GEN. The way a language ranks the universal set, that is CON, is the constraint hierarchy for that language. The points above are summarised by Archangeli (1997:13) thus: 'The input feeds into GEN, which creates candidates. The candidates are considered by EVAL, which selects the optimal candidates from the set'. This can be captured thus: 
Input $\rightarrow$ GEN $\rightarrow$ candidate $\rightarrow$ EVAL $\rightarrow$ Output

Adapted from McCarthy (2002:10)

OT could also work on the output to determine the input. This is especially useful in studies related to natural language perception (Archangeli, 1997:31).The OT schema will then be:

$$
\text { Output } \rightarrow \text { EVAL } \rightarrow \text { candidate } \rightarrow \text { GEN } \rightarrow \text { Input }
$$

The main assumption of OT is that the grammar of a particular language is a specific way, out of many possible ways, to rank a set of universal and violable constraints. This means that, by rearranging the basic universal material (reranking the constraints) of one language, we can build another grammar (Kager, 1999: 34).

The relation between universal constraints and language-particular ranking produces factorial typology (Prince \& Smolensky, 1993). This concept predicts that every permutation of the constraints in CON is a possible human language and that the grammar of every observed human language must be one of those permutations. However, it is not always the case that every permutation will produce an observably distinct human language. It is possible that two constraints in CON may not conflict on any candidate, just as CON may include universally fixed constraint hierarchies related on natural linguistic scales, which limit the typological consequences of ranking permutation. Therefore, it is necessary that an OT analyst tests the typological consequences of every proposed constraint and considers cross-linguistic variation of any phenomenon being analyzed (McCarthy 2002:12).

OT identifies two basic types of constraints, namely: faithfulness and markedness. Faithfulness constraints require identity between the input and the output, using the nature of the disparity between the input and the output supplied by GEN. Conversely, markedness constraints evaluate the form of the output candidate favouring a particular structure over others without making reference to the input (Moreton, 1996/1999). The phrase 'makedness constraints' refers to any constraint which assigns violation marks to a candidate based mainly on its output structure, not considering its similarity to the input. If a candidate is marked by or with respect to that constraint, it means such a candidate receives at least one violation-mark from it (McCarthy, 2002:14).

\section{The analysis}

\subsection{Background information on the subjects}

Only three of the subjects were left handed; the remaining 22 were right handed. The stroke affected the right side of 13 of them; it affected the left side of 10 of them; while it affected both sides of 2 of them. 12 of them had left hemispheric Cerebro-Vascular Disease (CVD), while 13 of them had right hemispheric CVD.

\subsection{Segmental phonology of the subjects}

The table below summarises the phonological processes noticed in the subjects.

Table 1. Summary of the phonological processes in the Broca's Aphasic

\begin{tabular}{|c|c|c|c|c|c|c|c|c|c|c|c|c|c|c|c|c|c|c|c|c|c|}
\hline \multicolumn{22}{|c|}{ DEVIATION } \\
\hline & \multicolumn{7}{|c|}{ Deletion } & \multicolumn{7}{|c|}{ Substitution } & \multicolumn{7}{|c|}{ Epenthesis } \\
\hline & \multicolumn{3}{|c|}{ Vowel } & \multicolumn{3}{|c|}{ Consonant } & & \multicolumn{3}{|c|}{ Vowel } & \multicolumn{3}{|c|}{ Consonant } & & \multicolumn{3}{|c|}{ Vowel } & \multicolumn{4}{|c|}{ Consonant } \\
\hline & In & Med & Fin & In & Med & Fin & Total & In & Med & Fin & In & Med & Fin & Total & In & Med & Fin & In & Med & Fin & Tota \\
\hline F & 1 & 6 & 4 & 56 & 35 & 72 & 174 & 8 & 61 & 20 & 86 & 37 & 55 & 267 & 4 & 6 & 21 & 17 & 23 & 20 & 91 \\
\hline$\%$ & 0.6 & 3.4 & 2.3 & 32.2 & 20.1 & 41.4 & 100 & 3.0 & 22.8 & 7.5 & 32.2 & 13.9 & 20.6 & 100 & 4.4 & 6.6 & 23.1 & 18.7 & 25.3 & 22.0 & 100 \\
\hline
\end{tabular}

As shown in Table 1, there were 174 instances of deletion. Only 1 involved vowels in word-initial position; 6 involved vowels in word-medial position; while 4 involved vowels in word-final position. As for consonants, 56 of the instances of deletion were in word-initial position; 35 were in word-medial position; while 72 were in word-final position. As for substitution, 8 affected vowels in word-initial position; 61 affected vowels in word-medial position; and 20 affected vowels in word-final position. 86 of the consonants substituted were found in word-initial position; 37 were found in word-medial position; while 55 were found in word-final position. Altogether, there were 267 instances of substitution. Epenthesis occurred 4 times in word-initial position; 6 times in word-medial position, and 21 times in word-final position. Instances of epenthesis involving consonants occurred 17 times in word-initial position; 23 times in wordmedial position; and 20 times in word-final position. Thus, there were 91 instances of epenthesis. 
The above analysis shows that in the Broca's aphasics, substitution accounts for about half of the total forms of deviation (50.2\%); deletion follows with 32.7\%; while epenthesis takes the remaining $17.1 \%$. Table 2 below captures this:

Table 2. Comparison of the deviation forms in the Broca's aphasics

\begin{tabular}{|l|c|c|}
\hline DEVIATION & $\mathrm{f}$ & $\%$ \\
\hline DELETION & 174 & 32.7 \\
\hline SUBSTITUTION & 267 & 50.2 \\
\hline EPENTHESIS & 91 & 17.1 \\
\hline TOTAL & 532 & 100 \\
\hline
\end{tabular}

Each form of deviation is now considered more carefully. As evident in Table 1, deletion did not affect vowels in wordinitial and word-final positions as such; word-medial vowels were the most affected, as 6 out of the 11 instances of vowel deletion occurred there. The same pattern is observable in substitution. More than half of the instances of vowel substitution occurred at word-medial position (61 out of 89 , which is $68.5 \%$ ). This suggests that, in Broca's aphasia, there is difficulty producing vowels not at either the word-initial or the word-final positions. In most cases, if a wordmedial vowel is not deleted, it is substituted. As shown in Table 1, more than half of the instances of vowel epenthesis occurred at word-final position; out of 31 instances of epenthesis, 21 (68.0\%) occurred at word-final position.

For us to have a convincing account of why the Broca's aphasics had much difficulty with word-medial vowels, it is expedient to examine the type of sounds that surround medial-vowels. English permits optional onset and optional coda, which are necessarily consonants. There can be no medial position if there are no initial and final positions. This means that medial vowels are bounded by consonants both at the left and at the right. It is also possible that the onset and coda are made up of consonant clusters.

Looking at Table 1, with respect to deletion, we find in the consonants the opposite of what obtains in vowels. Consonants in word-initial and word-final positions were more greatly affected than word-medial consonants. The most greatly affected were word-final consonants (72 out of 163 instances). Substitution shows a similar trend. Word-initial and word-final consonants got substituted more than word-medial consonants. However, word-initial consonants were the most affected by substitution (86 out of 178 instances (48.3\%); word-final consonants followed with $30.9 \%$ (55 out of 178 instances). It is only consonant epenthesis that shows a slightly different pattern, where the frequency of consonant epenthesis at word-medial position is slightly greater than those of the other two word positions. We can take consonant epenthesis to be almost evenly distributed across the three word-positions. Word-initial position has $28.3 \%$ (17 out of 60 instances of consonant epenthesis); word-medial position has 38.3\% (23 out of 60 instances of consonant epenthesis); word-final position has $33.3 \%$ (20 out of 60 instances of consonant epenthesis).

\subsubsection{Deletion}

The inverse relation noticed in the deletion and substitution of vowels and consonants appears to be the brain's way of compensating with the one what has been lost by the other. The deletion of segments suggests that the initiation of speech is usually difficult for Broca's aphasics. If the word begins with a vowel, there is usually no problem. But if it begins with a consonant, there is great difficulty. This is because, in the production of vowels, the airstream escapes unobstructed. As long as a human being still breathes, producing a vowel might not be so difficult; when the airstream escapes from the lungs, even if no audible sound is heard, there will be a form of whisper (Jones, 1976:19).

Speech production is a voluntary action, requiring that the organs of speech are placed in certain definite positions or moved in certain definite ways (Jones, 1976:1). This presupposes that, once there is damage to the frontal lobe (whose functions include speech production) this voluntary action becomes difficult to initiate. The attempt by an aphasic to forcefully produce a word is, perhaps, responsible for the deletion of consonants in word-initial position. It seems plausible that, after the initial difficulty encountered, once speech is initiated, the damaged neurons get activated. This is why the rate of deletion of consonants in word-medial position is reduced. But it appears that the tempo cannot be maintained; before the production of the word is completed, more consonants in word-final position are deleted. Therefore, we can liken the neurons to the battery of a vehicle. In a non-aphasic individual, the battery is fully charged and functions well. Thus, starting such a car and accelerating are not difficult. This is why initiating speech and maintaining it is not difficult for non-aphasic humans. On the contrary, in aphasics, damage to the brain runs down and weakens the battery. In such a case, trying to force speech out is analogous to trying to start a car with a weak battery. After some trials and pushing, the car may start and work for a while. But it may soon stop. By the same token, the desperate efforts made by a Broca's aphasic to produce speech leads to deletion of consonants at the beginning of a word. The neurons appear to be partially active and assist necessary organs of speech. But because of the severity of the damage, producing many sounds with strictures becomes difficult. It should be noted that in the production of consonants, there are strictures at various positions. In fact, the degree of the stricture determines the type of consonant deleted.

Table 3 below shows the sounds that were mostly affected by deletion. 
Table 3. Sounds most affected by deletion in the speech

of the Broca's aphasics

\begin{tabular}{|c|c|c|c|}
\hline \multicolumn{2}{|c|}{ Consonants } & $\mathrm{f}$ & $\%$ \\
\hline \multicolumn{2}{|l|}{$/ \mathrm{t} /$} & 29 & \\
\hline \multicolumn{2}{|l|}{$/ \mathrm{d} /$} & 28 & \\
\hline Plosives & Plosives & 20 & 48.0 \\
\hline \multicolumn{2}{|l|}{$\lg /$} & 4 & \\
\hline \multicolumn{2}{|l|}{$/ \mathrm{b} /$} & 2 & \\
\hline \multicolumn{2}{|l|}{$/ \mathrm{r} /$} & 26 & \\
\hline \multicolumn{2}{|r|}{ Fricatives } & 18 & 31.2 \\
\hline \multicolumn{2}{|l|}{$/ \mathrm{h} /$} & 8 & \\
\hline & 2 & \\
\hline \multirow{2}{*}{$\begin{array}{l}/ \mathrm{n} / \\
/ \mathrm{m} /\end{array}$} & Nasals & 18 & 11.7 \\
\hline & & 2 & \\
\hline$/ 1 /$ & Lateral & 2 & 1.2 \\
\hline \multirow{2}{*}{$\begin{array}{l}/ \mathrm{w} / \\
/ \mathrm{j} /\end{array}$} & Semi vowels & 12 & 8.1 \\
\hline & & 2 & \\
\hline \multicolumn{2}{|c|}{ Total } & 173 & 100 \\
\hline
\end{tabular}

According to this table, out of the 173 cases of deletion, almost half (48\%) were plosives. This is because plosives have 'the most extreme type of stricture' (Abercrombie, 1967:44). The organs of speech involved in the production of plosives make firm contact with each other and the sound is released suddenly like an explosive. Among the plosives deleted, bilabial plosives, /p/ and /b/, were almost absent; only /b/ was affected twice. An explanation for this could be sought in the place of articulation. The two lips are involved, unlike in the other plosives in which the most mobile articulator (the tongue) is also involved. This suggests that the degree of the involvement of the tongue is a crucial determinant in the consonant to be deleted. This fact is supported by the high number of cases of deletion involving the alveolar plosives, /t/ and /d/. In these plosives, the tongue makes a firm contact with the alveolar ridge. The kind of contact the back of the tongue makes with the velum does not involve exactly the same amount of force as the one the tip of the tongue makes with the alveola.

As shown in the table, fricatives have $31.2 \%$. The production of fricatives involves narrowing of the air-passage so that the airstream escapes with a kind of hissing sound (Jones, 1976:179). This reduction in pressure could be responsible for the cases of their deletion not being as high as those of plosives.

The deletion of other consonants is not as serious as that of the aforementioned ones. The cases of deletion of /w/ involved the co-occurrence of $/ \mathrm{w} / \mathrm{with} / \mathrm{k} /$ in quickly. In other instances of its occurrence, $/ \mathrm{w} /$ was not deleted. The cases of the deletion of $/ \mathrm{n} /$ involved $/ \mathrm{n} /$ in word-final position.

Only two vowels were seriously affected by deletion. Out of the 13 cases of deletion of vowels, 11 involved / I/, while 2 involved / $\mathrm{o} /$. II/ is a weak sound, which can also occur where /ə/ occurs. This might be responsible for its deletion. The neural pathway for its production has already been weakened and the sound itself is weak. These two factors work against the production of /I/ by the Broca's aphasics.

\subsubsection{Substitution}

Substitution alone accounts for half (50.2\%) of the forms of the deviation in the speech of the Broca's aphasics (see Table 2). A major reason for this is the inability of the aphasics to reach the target sound. They, therefore, approximated to a sound that either shares the same place of articulation or the same manner of articulation with the target consonant. If it was a vowel, they approximated to another one that is roughly similar to the target one either by changing a monophthong to a diphthong or by producing another monophthong whose production requires less effort.

Vowel substitution occurred mainly in word-medial position. This was possibly due to the fact that some energy had been expended at the beginning of the word. Another possible reason is mother tongue interference, which is conspicuously noticed in the vowel inventory of Nigerian English (NE). A good number of the vowels in NE are completely different from those in RP. For instance, /I/ is almost absent in NE; instead, /i/ (which is between /I/ and /i:/) is used for both /I/ and /i:/ Similarly, in NE /o/ is often used for /əU/, just as /Ia/ is often used for /Iə/ (Akinjobi, 2004). An important reason for this is that most Nigerian indigenous languages have vowels that are roughly similar to those of RP. Most speakers of NE, therefore, transfer wholesale the vowel inventory in their $\mathrm{L}_{1}$ to that of English. Of all the vowels, /I/ was the one mostly affected by substitution. There were predominantly three vowels that were used in its place, as shown in Table 4 below 
Table 4. Substitutes of /I/

\begin{tabular}{|l|l|c|}
\hline & f & $\%$ \\
\hline$/ \mathcal{E} /$ & 20 & 58.8 \\
$/ \mathrm{UI} /$ & 9 & 26.8 \\
$/ \mathrm{a} /$ & 5 & 14.7 \\
\hline Total & 34 & 100 \\
\hline
\end{tabular}

This table shows that /I/ was realized as / $\varepsilon /$ in most cases. /UI/, which follows / $/$ / in frequency is not an RP diphthong. This diphthong is often used in NE in sequences involving /W/ and /I/, as in quickly; /W/ is often deleted and replaced with / $/$. This substitution involves gliding: /w/ is derived from $/ \mathrm{U} /$ through gliding, the same way $/ \mathrm{j} /$ is realized from /I/ through gliding. Rather than having the glide /w/, NE speakers often have /u/. This pattern was noticed in the speech of the subjects. They particularly found it difficult to produce /w/ in the sequence / kwIkl工/. This word is part of the

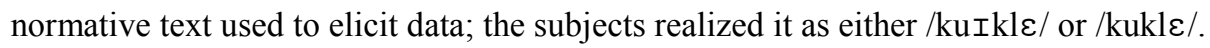

There were other vowels substituted but they did not show any consistency, unlike /I/. For example, /ə/ was realized as /o/, /u/, or / o/; /a:/ was realized as /av/, /o/ or /a/; /uə/ as /ua/; and /Iə/ as /Ia / or /e/.

In most cases, the speech of each of the Broca's aphasics was marked by pauses within utterances and within words. This made their speech staccato in form. It was as if they pronounced the words in isolation. This was because they required much effort in speech production. It is then not surprising that initial and final consonants got modified in the course of their production, when they were not deleted. At times, however, they got the target sounds. Most of the cases of substitution involved consonant clusters. Word-medial consonants were not as seriously affected as those in the other two word positions, perhaps, because, by the time of their production, the neurological pathway was still agile. As seen in Table 1, consonant substitution was more prominent at word-initial position than the other two word positions. A reason for this is possibly the energy the neurons needed in initiating speech production at the beginning and after each pause.

Almost all consonants were affected by substitution. Most of the instances of substitution, however, did not follow a rigid pattern. For example, /g/ was realized as /d/ (e.g. dandchildren for grandchildren); /k/ as /S/, /f/, /d/ /h/, e.g. dannot for cannot; /g / as /w/ (e.g. wadually for gradually); /p/ as /t/ (e.g. tout for proud); /f/ as /d/ or /w/ (e.g. dully for fully; waget for forget); / $/$ as /j/ (e.g. yallenge for challenge.

Few of the consonants, nevertheless, displayed some regularity in substitution pattern. Table 5 below shows the most frequently affected ones.

Table 5. Regularly substituted consonants in the speech of the Broca's aphasics

\begin{tabular}{|c|c|c|}
\hline Consonant & Substitute & $\mathrm{f}$ \\
\hline$/ \mathrm{s} /$ & $/ \mathrm{t} /$ & 48 \\
\hline$/ \mathrm{d} /$ & $/ \mathrm{t} /$ & 15 \\
\hline$/ \mathrm{s} /$ & $/ \mathrm{d} /$ & 14 \\
\hline$/ \mathrm{t} /$ & $/ \mathrm{d} /$ & 12 \\
\hline$/ \mathrm{t} /$ & $/ \mathrm{s} /$ & 8 \\
\hline Total & & 97 \\
\hline
\end{tabular}

This table shows that /s/ was the mostly substituted consonant. As shown in Table 1, there were 178 instances of consonant substitution in the speech of the Broca's aphasics. /s/ alone got substituted as /t/ 48 times or /d/ 14 times. Altogether, these amounted to $34.8 \%$. Table 5 also shows that some of the subjects interchanged $/ \mathrm{t} /$ and $/ \mathrm{d} /$; /d/ was substituted as /t/ 15 times, while the reverse occurred 12 times. The two consonants only differ with respect to their phonation: / $/$ / is voiceless alveolar plosive while /d/ is voiced alveolar plosive. Table 5 also indicates that some instances of the realization of $/ \mathrm{t} / \mathrm{as} / \mathrm{s} /$ occurred.

Essentially, therefore, substitution in the speech of the subjects under analysis often involved $/ \mathrm{s} /, / \mathrm{t} / \mathrm{and} / \mathrm{d} /$. Incidentally, they are all alveolar sounds. It appears that alveolar sounds are the most difficult sounds for bilingual Nigerian aphasics. Table 5 lends credence to this. The alveolar sounds deleted and their frequencies of occurrence are as follows: /t/ 29, /d/ 28, /r/ 26,/s/ 18,/n/ 18,/t/ and /1/ 2. Altogether, 121 out of 163 instances of consonant deletion (which is 74\%) involved alveolar consonants. Table 5 shows that all the 97 most frequent cases of substitution involved alveolar sounds. The question now is: what are the peculiarities of alveolar sounds?

Alveolar sounds are those sounds produced with the tip or the blade of the tongue touching the teeth ridge (Jones, 1976:45). The difficulty Broca's aphasics have with alveolar sounds must then be due to the fact that the neurological pathway needed for the movement of the tongue to the teeth ridge is more tortuous than the movement needed by the articulators in the other places of articulation. Interestingly, out of the 24 English consonants 7 are alveolars (/t, d, s, z, $\mathrm{n}, \mathrm{l}, \mathrm{r} /$ ). There is no other place of articulation that has as high as this number.

5.2.3 Epenthesis

Insertion of segments - epenthesis - was not as common as the other two forms of deviation. Incidentally, the vowel most often deleted - /i/ - was also the one most often inserted. Out of the 31 instances of vowel epenthesis, /i/ was involved 28 times $(90.3 \%)$, the remaining 3 instances involved /u/ $(9.7 \%)$. /i/ is half-close front unrounded short vowel. In $\mathrm{NE}$, it is in free variation with /I/ and / i:/ in all environments. Vowel epenthesis achieves the purpose of simplification of syllable structure. English permits consonant clusters, which, sometimes, are difficult even for some 
non-aphasic Nigerian adults, let alone aphasics. In cases where the consonant clusters proved extremely difficult to articulate and the aphasic did not want to delete or substitute any of the consonants, s/he resorted to vowel epenthesis. Expectedly, this affected the structure of the syllables in the word. The number of the syllables increased by the number of the times vowels were inserted, since vowels form syllable peaks (syllabic consonants too occupy syllable peaks occasionally).

The most often inserted consonant was $/ \mathrm{n} /$. It accounted for 25 out of the 60 instances of consonant epenthesis noticed. This is $41.7 \%$. Other consonants significantly affected were $/ \mathrm{d} /-8$ times $(13.3 \%)$ and $/ 1 /-4$ times $(6.7 \%)$. The remaining instances were shared by $/ \mathrm{j}, \mathrm{k}, \mathrm{s}, \mathrm{w}, \mathrm{m}, \mathrm{t} /$. The subjects who mostly inserted $/ \mathrm{n} /$ were those whose mouths were seriously disfigured by the stroke; their mouths twisted to either left or right. The twisting seriously affected their speech production. Even when those subjects did not outright add $/ \mathrm{n} /$, traces of nasalization of vowels not immediately followed by a nasal consonant were perceived in their speech. This suggests that the airstream escapes more easily through their nasal cavities in the course of speech production. Of the three English nasal consonants only $/ \mathrm{n} /$ is seldom used by NE speakers. This is a reason it could not be a possible nasal to be inserted. For aphasics with twisted mouths, $/ \mathrm{n} /$ was easier to produce than $/ \mathrm{m} /$ because it is only the tongue that has to move in its articulation; the production of $/ \mathrm{m} /$ involves the two lips coming in contact. Besides, the configuration of the oral and nasal cavity after the mouth has been disfigured makes $/ \mathrm{n} /$ easier to produce with little movement of the tongue. $/ \mathrm{n} / \mathrm{w}$ ws inserted at word-medial and wordfinal positions. This means that speech production would have started before the insertion. The sounds preceding or following the insertion of $/ \mathrm{n} /$, in most cases, were nasals. Thus, the epenthesis of $/ \mathrm{n} /$ involves the patients either regressively or progressively assimilating the place of articulation of the sound it co-occurs with.

5.2.4 Ranking of constraints in bilingual Nigerian adult Broca's aphasics

The instances of deviation discussed above present interesting issues about constraints ranking. To capture these issues vividly, we need to examine some examples of each form of deviation, so as to see the relationship between the input and the output candidates. This analysis adopts an endonormative approach, using the variety of World English the subject acquired before the brain damage, which is NE. The aim of this is to present an analysis that will be useful for speech therapy. To clearly see the necessity of this analytic approach, the RP version of each structure analyzed is presented alongside the subjects' and the NE varieties.

Examples of each form of deviation are first presented before considering how some of the candidates emerged as optimal outputs.

\section{Substitution}

\begin{tabular}{|c|c|c|}
\hline 1. tont & [tont] & for tongue \\
\hline 2. appreted & [apreted] & for arrested \\
\hline 3. polit & [polit] & for police \\
\hline 4. breaquast & [brekwast] & for breakfast \\
\hline 5. resmonded & [resmonded] & for responded \\
\hline 6. toctor & [tokto] & for doctor \\
\hline 7. adone & [عdon] & for alone \\
\hline 8. mashnic & [mæ S nik] & for mechanic \\
\hline 9. mik & [mit] & for meat \\
\hline 10. pway & [pwe] & for pray \\
\hline
\end{tabular}

\begin{tabular}{|c|c|}
\hline NE & $\mathbf{R P}$ \\
\hline $\begin{array}{l}\text { /tong/ } \\
\text { / rested/ } \\
\text { /polis / }\end{array}$ & $\begin{array}{l}\text { /t^y/ } \\
\text { /rested/ } \\
\text { /pəli:s/ }\end{array}$ \\
\hline /bre kfa:st/ & /breIkfa:st/ \\
\hline /responded/ & /respondId / \\
\hline /dokto / & /doktə/ \\
\hline /Elon/ & /ələun/ \\
\hline $\begin{array}{l}\text { /mekænik/ } \\
\text { /mi:t/ } \\
\text { /prধ/ }\end{array}$ & $\begin{array}{l}\text { /mIkænIk/ } \\
\text { /mi:t/ } \\
\text { /preI/ }\end{array}$ \\
\hline
\end{tabular}

\section{Deletion}

\begin{tabular}{|c|c|c|c|c|}
\hline 1. fluntly & [flentle] & for fluently & /fluentle/ & /flu:əntlı/ \\
\hline 2. etatit & [etat] & for exercise & /eksæsaIs/ & /eksəsaIs/ \\
\hline 3. yesiday & [jeside/ & for yesterday & /jestædeI/ & /jestədeI/ \\
\hline 4. tout & {$[\operatorname{taut}]$} & for proud & /praud/ & /praud/ \\
\hline 5. ice & [aIs] & for rice & /raIs/ & /raIs/ \\
\hline 6. allenge & [ælendz/ & for challenge & /t æælendz/ & $/ \mathrm{t} \int æ l I n d z /$ \\
\hline 7. adam & [ædæm] & for madam & /mædæm/ & /mædəm/ \\
\hline 8. sponded & [sponded] & for responded & /responded/ & /rIspondId/ \\
\hline 9. arrested & [æresed] & for arrested & /ærested/ & /ərestId/ \\
\hline 10. ank & [ænk] & for thank & /tænk/ & /Өæりk/ \\
\hline 11. dug & [dog ] & for drug & /drog / & /dr^g/ \\
\hline
\end{tabular}




\section{Epenthesis}

1. normanlly

2. tipik

3. waki

4. asathack [æsætæk]

5. yam [jæm]

6. prould [provild]

7. fak [fæk]

8. mine [maIn]

9. hunsband [honsbænd]
NE

/nomæle/

/spik/

/wok/

/ætæk/

/æm/

/praud/

/ka:/

/maI/

/hosbænd/

\section{RP}

/noməlI/

/spi:k/

/wo:k/

/ətæk/

/æm/

$/ p r a u d /$

/ka:/

/maI/

/h^sbənd/

How constraints are ranked in cases involving substitution is now discussed. 'Polit' and 'dannot' are used to illustrate. Tableaux 1 and 2 show the constraints ranking for each of these words, respectively.

Tableau 1. The emergence of /polit/

Input /pəlIs/ $\rightarrow$ Output /polit/

\begin{tabular}{|c|l|c|c|}
\hline pəli:s/ & $*$ IDENT (manner) & IDENT (round) & FAITH C \\
\hline poli:s & $* !$ & $*$ & \\
\hline polis & $* !$ & & \\
\hline polit & & & $*$ \\
\hline
\end{tabular}

Tableau 2. The emergence of /dænot/

Input / kænot / (cannot) $\rightarrow$ Output / dænot /

\begin{tabular}{|l|l|l|l|}
\hline / kænot/ & *IDENT (place) & *IDENT (voice) & FAITH C \\
\hline (i) kænot & $* !$ & $*$ & \\
\hline (ii) dænot & & & $*$ \\
\hline
\end{tabular}

Three constraints are involved in this ranking. One of them is ranked in the opposite form, with $(*)$ which indicates unacceptability. This means that in the phonology of the aphasics, such constraint is unacceptable, though it is acceptable in the phonology of non-aphasic adults. It is only in this way that we can account for the emergence of their optimal output candidates. This means that, the aphasics too use the constraints that non-aphasic adults use, only that they rank them in the opposite form of how non-aphasic adults use them. The implication of this is that there is a section of the brain meant for ranking constraints and that damage to the cortex makes them work in a direction opposite to what obtains in non-aphasic adults. Consequently, the constraints in the phonology of non-aphasic adults are unacceptable to them. Since the focus of OT is on the output, the analysis has to consider the nature and ranking of the aphasics' constraints, which have resulted in the peculiar optimal outputs. The argument here is that, if the analysis sees them as violating the constraints of the non-aphasic adults, it will be impossible to arrive at their optimal outputs, as such outputs will unavoidably incur many lowest violations; whereas, 'the optimal candidate should be one with the fewest lowest violations' (Archangeli, 1997:12). The three constraints involved in the emergence of 'polit' as the optimal output are:

a. *IDENT (manner): that allows difference in the manner of articulation between the input and the output, contrary to IDENT (manner).

b. IDENT (round): which requires that the vowel should be rounded.

c. FAITH C: which requires faithfulness of consonants between the input and the output (Archangeli, 1997:11).

The optimal output in Tableau 1 differs from the input with regard to mainly two segments $-/ ə /$ and /s/. / i / is only slightly different from /i:/, in that it is not as long as /i:/. This segment is disregarded in the analysis because it is not all that significant. As shown in the tableau, three constraints are involved in this ranking: IDENT (manner), *IDENT (round), and FAITH C. The RP output candidate violates two of these constraints. It violates *IDENT (manner) because it contains $/ \mathrm{s} /$, which differs from $/ \mathrm{t} / \mathrm{in}$ manner of articulation. $/ \mathrm{s} /$ is voiceless alveolar fricative, while /t/ is voiceless 
alveolar plosive. Though the input contains $/ \mathrm{s} /$, this output candidate fails to emerge as the optimal candidate because the aphasic's language faculty disallows sameness of manner of articulation between the input and the output, with respect to this segment. The RP output candidate violates IDENT (round) because it contains /ə/, which is an unrounded vowel. The NE candidate violates only *IDENT (manner). The optimal output violates only FAITH C, which requires that the consonants in the output should also be present in the input, as it contains $/ \mathrm{t} /$ instead of $/ \mathrm{s} /$. It emerges as the optimal candidate because the other two output candidates fatally violate *IDENT (manner); besides, the RP output candidate violates IDENT (round). The violation by the output candidate of the aphasic is not fatal, since IDENT (manner) dominates the other two constraints: *IDENT (manner) >> IDENT (round), FAITH C. In other words, FAITH C is lowly ranked by this aphasic.

The emergence of 'dannot', shown in Tableau 2, involves three constraints:

*IDENT (place): that allows difference in the place of articulation between the input and the output

*IDENT (voice): which disallows sameness of voicing between the input and the output

FAITH C: which requires faithfulness of consonants between the input and the output (Archangeli, 1997:11).

The output of the aphasic contains /d/, voiced alveolar plosive, whereas the input contains $/ \mathrm{k} /$, voiceless velar plosive. The patient ranked the constraints thus: *IDENT (place) >> *IDENT (voice) >> FAITH C. This means that FAITH C is lowly ranked; as such, its violation does not disallow /dænot/ from emerging as the optimal output. / kænot / (NE and RP output candidate) does not emerge as the optimal output because it fatally violates *IDENT (place), which are dominated by FAITH C.

The foregoing analysis shows that the substitution process involves $\mathrm{M}>>\mathrm{F}$; that is, markedness dominating faithfulness. In addition, the markedness constraints are in forms opposite to what is seen in the phonology of non-aphasic adults, due to brain damage.

Constraints ranking in cases involving deletion are now considered. (M)adam and (d)rug are used to illustrate.

Tableau 3: The emergence of /ædæm/ Input / mædəm / madam $\rightarrow$ / ædæm /

\begin{tabular}{|c|c|c|c|}
\hline$/ \mathrm{mæd} ə \mathrm{~m} /$ & $* \mathrm{MAX}$ & $*$ ONSET & FAITH C \\
\hline mædəm & $* !$ & $*$ & \\
\hline ædæm & & & $*$ \\
\hline
\end{tabular}

Tableau 4: The emergence of / dog/

Input / dr^g/ (drug) $\rightarrow$ Output / dog /

\begin{tabular}{|c|c|c|c|c|}
\hline$/$ dr^g / & ${ }^{*}$ COMPLEX & ${ }^{*}$ MAX & IDENT (round) & FAITH C \\
\hline (i) dr^g & $* !$ & $* !$ & $*$ & \\
\hline (ii) drog & $* !$ & $* !$ & & \\
\hline (iii) dog & & & & $*$ \\
\hline
\end{tabular}

The deviation in '(m)adam' involves the deletion of voiced bilabial nasal in onset position. There are two output candidates, as shown in Tableau 3: /mædəm/ and /ædæm/. The aphasic ranks *MAX and *ONSET higher than FAITH (C): *MAX, *ONSET >> FAITH C. *MAX allows deletion, since MAX states that every segment/feature of the input has an identical correspondent in the output (see Pulleyblank, 1997:63 for Max). *ONSET allows a syllable not to have onset. /ædæm / emerges as the optimal candidate, whereas /mædəm/, which obeys FAITH C, fails to emerge as the optimal candidate, because it violates*ONSET and fatally violates *MAX.

The realisation of 'd(r)ug' involves four constraints: *COMPLEX, which disallows consonant clusters; *MAX, which allows deletion; IDENT (round), which requires that the vowel in the input and the output must be rounded; and FAITH $\mathrm{C}$, which requires sameness in the consonant in the input and the output. The RP and the NE output candidates fatally violate *COMPLEX because they allow consonant cluster $/ \mathrm{dr} /$ at the onset of the syllable. They also fatally violate *MAX, as they do not allow the deletion of /r/. The RP candidate also violates IDENT (round), since it does not have a round vowel. The aphasic candidate (iii) violates only FAITH C, because not all its consonants are faithful to the input; $/ \mathrm{r} /$ has been deleted. This optimal candidate simplifies the onset, making it only one consonant instead of two consonants. However, it is able to emerge as the optimal candidate because FAITH C is lowly ranked in the language area of the patient. The four constraints are ranked thus: *COMPLEX $>>*$ MAX $>>$ IDENT (round), FAITH C.

In sum, therefore, deletion in the phonology of bilingual Nigerian adult Broca's aphasics reveals that they rank FAITH C low and rank *MAX, *ONSET and *COMPLEX high. This is contrary to what is noticed in the phonology of the nonaphasic adults. 
The third form of deviation, epenthesis, is now considered. 'Mine' and 'walki' are used to illustrate. Tableaux 5 and 6 show the ranking of constraints in each of them.

Tableau 5: The emergence of /maIn/

Input $/ \mathrm{maI} /(\mathrm{my}) \rightarrow$ Output / maIn/
\begin{tabular}{|c|c|c|}
\hline$/ \operatorname{maIn} /$ & $* \mathrm{DEP}$ & CODA \\
\hline $\operatorname{maIn}$ & & $*$ \\
\hline $\mathrm{maI}$ & $* !$ & \\
\hline
\end{tabular}

Tableau 6: The emergence of /woki/

Input/ wo:k / (walk) $\rightarrow$ output / woki /

\begin{tabular}{|c|c|c|c|}
\hline / wo:k / & ${ }^{*}$ DEP & IDENT(length) & FAITH (๑) \\
\hline wo:k & $* !$ & & \\
\hline woki & & ${ }^{*}$ & $*$ \\
\hline wok & $* !$ & ${ }^{*}$ & \\
\hline
\end{tabular}

For the input /maI/, there are two output candidates and two constraints. The constraints are ranked as *DEP $>>$ CODA. /maI/ violates only CODA, which requires that a syllable must have coda. Thus, /maIn/ emerges as the optimal candidate.

In Tableau 6, three constraints are involved in the ranking. The output candidates that fail to emerge as the optimal candidate fatally violates *DEP, which permits segment insertion; these candidate disallow the insertion of $/ \mathrm{i} / \mathrm{after}$ the word. The RP candidate violates only one constraint but it could not emerge as the optimal candidate because this constraint is highly ranked. The second candidate violates IDENT (length), as it contains a short vowel instead of a long vowel; the NE candidate also violates this constraint. The aphasic candidate is the only one that violates FAITH (๑), which requires sameness in the number of syllables in the input and the output. Its violation of FAITH (๑) makes it to have two syllables instead of one syllable, which the input has. The emergence of this candidate as the optimal candidate is possible because the constraints are ranked as *DEP, *IDENT (length) >> FAITH (๑).

The instances of epenthesis just analysed also show that markedness often dominates faithfulness $(M>>F)$ in the phonology of the aphasics.

\section{Recommendations}

One of the key issues that the findings of this research bring to the fore is that substitution and deletion of segments are the most predominant phonological processes in the speech of bilingual Nigerian adult aphasics. Therefore, the speech therapist needs to take note of the segments often substituted or deleted and their properties. To achieve effect in the speech therapy, the phonology the patient had before brain damage should be the basis of the assessment. This will help in determining the type of exercise to administer to the patient. If a variety of the language that is strange is used as the baseline, the therapy may not be productive. It may appear as if the patient is not responding. The result of this will be discouragement to the patient, the speech therapist and other caregivers.

It is important to incorporate neurolinguists into the rehabilitation of aphasics. They serve as an important source of information on how other therapists can effectively interact with aphasics. They can do this through generating some generalisations on the phonology of each patient by studying how he or she ranks constraints. The constraints that are ranked highest by the aphasics will also assist the speech therapist in knowing the particular sound to focus on.

\section{Conclusion}

The analysis of the segmental features of the phonology of the subjects reveals certain peculiarities of the phonology of Nigerian adult aphasics. The phonology of these subjects was described by using NE phonology as the standard. The main reason behind this is that this is the phonology they had before the brain damage. If RP was used, the result would not be a true picture of the phonology of these people. Besides, using NE phonology as the standard provides the speech therapist with reliable data for the treatment of the aphasics.

The analysis shows that consonants were more affected than vowels. In the speech of the Broca's aphasics studied, substitution affected consonants in word-initial and word-final position more than consonants in word-medial position. However, vowels in word-medial position were more affected by substitution than those in the other two word positions. Deletion of segments affected consonants in word-initial and word-final positions more than those in wordmedial position. Vowel deletion affected those vowels in word-medial position more than those in the other two word positions. Consonant epenthesis was more predominant in word-medial position than the other two word positions. Vowel epenthesis featured at word-final position more than the other two word positions.

The stricture associated with the production of consonants was largely responsible for their being affected by substitution and deletion more than vowels were. The high occurrence of consonant epenthesis in the aphasics was due to the high occurrence of the nasal $/ \mathrm{n} /$ in the speech of some of the patients. 
The analysis also reveals that deletion of consonants affected plosives more than consonants with other manners of articulation. This is because plosives have the most extreme stricture. The place of articulation also exerted a great influence on deletion. Alveolar consonants were more affected by deletion than other consonants. This is because greater energy seems to be needed for the movement of the tongue to the alveola ridge. Bilabial plosives were almost unaffected by deletion, owing to the fact that their articulation involves the two lips, which are almost always in contact during speech production. Substitution of consonants involved mainly /s, t, d/; they were substituted for one another. But the substitution of $/ \mathrm{t} /$ for $/ \mathrm{s} /$ was more common. These three sounds often substituted are alveolar consonants. Vowel substitution involved mainly /I /. This is a weak vowel often found in unstressed syllable. /I/ was often realized as /E/.Epenthesis of consonants involved /n/ mostly. /i/ was the mostly inserted vowel. Insertion of vowels was a strategy of simplifying consonant clusters. Vowel insertion resulted mainly because of the difficulty associated with pronouncing syllabic consonants. Insertion of consonants was mainly due to the addition of $/ \mathrm{n} /$. It was common in subjects with disfigured mouths.

The analysis of how constraints were ranked by the aphasics shows that the ranking is contrary to what obtains in nonaphasic adults. It also shows that the language area of these subjects ranks Markedness above Faithfulness (M $>>F)$. In their phonology, certain constraints are marked and seen as being more important than others.

The findings of this work also show that the segments are not equally affected. Plosives and alveolars were more affected by deletion and substitution than any other class of consonants. This suggests that the brain is so specialized that different sections in it handle different classes of sounds. Otherwise, the sounds should have been equally affected.

\section{References}

Abercrombie, D. (1967). Elements of general phonetics. Edinburgh: Edinburgh University Press.

Akinjobi, A. (2004). A phonological investigation of vowel weakening and unstressed syllable obscuration in Educated Yoruba English. Ph.D. Thesis. Department of Linguistics and African Languages. University of Ibadan, Ibadan.

Archangeli, D. (1997). Optimality Theory: An introduction to linguistics in the 1990s. Optimality Theory: an overview. D. Archangeli and Langendeon D.T. Eds. Oxford: Blackwell Publishers, 1-32.

Bamgbose, A. (1971). The English Language in Nigeria. Spencer J. ed. The English Language in West Africa, London: Longman.

Banjo, A. (1996). Making a virtue of necessity: An overview of the English language in Nigeria. Ibadan: Ibadan University Press.

Blumstein, S.E. (1973). A phonological investigation of aphasic speech, The Hague: Mouton.

Blumstein, S.E. (1988). Neurolinguistics: An overview of language-brain relations in aphasia. Linguistics: the Cambridge survey, vol.3: Language: psychological and biological aspects. F.J. Newmeyer. Ed. Cambridge: Cambridge University Press. 210-236.

Bouman, L. \& Grunbaum, A. (1925). Experimentell - Psychologische Untersuchungen zur Aphasie and Paraphasie. Zietschirift für gesanite Neurologie and Psychiatrie 96:481-538.

Caplan, D. (2003). Neurolinguistics. The handbook of linguistics, M. Aronff and J. Rose-Miller Eds. Oxford: Blackwell.582-607.

Cartell, R. (2006). An introduction to mind, consciousness and language.London and New York: Continuum.

Congress on Child Language and Disorders. (2006). Call for papers. University of Port Harcourt, Port Harcourt.

Crystal, D. (1987).The Cambridge encyclopedia of language. Cambridge: Cambridge University Press.

Edwards, S. (2002). Aphasia. The linguistics encyclopedia. K. Malmkjær. Ed. London and New York: Rougledge.17 21.

Fox, A. (2002). Generative Phonology . The linguistics encyclopedia. 2nd Ed K.Malmakjær. Ed. London and New York: Routledge. 193-199.

Goldstein, K. (1948). Language and language disturbances.New York: Grune and Straton.

Goodglass, H. \& Kaplan, E. (1983). The assessment of aphasia and related disorders. 2nd Ed. Philadelphia: Lea.

Goodglass, H., Gleason, J., Bernholtz, N.A. \& Hyde M.R. (1972). Some linguistic structures in the speech of a Broca's aphasic. Cortex. 8: 191-212.

Hammond, M. (1997). Optimality Theory and prosody. Optimality Theory: an overview. D. Archangeli and Langendeon D.T. Eds. Oxford: Blackwell Publishers. 33-58.

Jones, D. (1976). An outline of English phonetics. Cambridge: Cambridge University Press.

Kager, R. (1999). Optimality Theory. Cambridge: Cambridge University Press.

Kujore, O. (1985). English usage: some notable Nigerian variations. Ibadan: Evans Brothers.

Lecours, A.R. \& Lhermitte, F. (1969). Phonemic paraphasias: Linguistic structures and tentative hypothesis. Cortex 5:193-228. 
Luria, A.R. (1966). Higher cortical functions in man. New York: Basic Books.

McCarthy, J. (2002). A thematic guide to Optimality Theory. Cambridge: Cambridge University Press.

McCarthy, J. \& Prince, A. (1995). Faithfulness and reduplicative identity University of Massachusetts occasional papers in linguistics 18. J. Beckman, L.W. Dickey and S. Urbanczyk. Eds. Amherst, MA: GLSA. 249-384.

Moreton, E. (1996/1999). Non-computable functions in Optimality Theory. Unpublished Manuscript, Amherst: University of Massachusetts. (Written in 1996; revised and placed on Rutgers Optimality Archive in 1999).

Niemi, J. Koivuselka-Sallimen, P. \& Hanninen, R. (1985). Phoneme errors in Broca's aphasia: three Finnish cases. Brain Language 26:28-48.

Oyeabade, F. (1998). A course in phonology. Ijebu-Ode: Shebiotimo Publications.

Parker, F. 1986. Linguistics for non-linguists. San Diego: College-Hill Press.

Peuser, G. \& Fittshen, M. (1977). On the universality of language dissolution: the case of a Turkish aphasic. Brain and Language. 4:196-207.

Pulleyblank, D. (1997). Optimality Theory and features. Optimality Theory: an overview. Archangeli D. and Langendeon D.T. Oxford: Blackwell Publishers. 59-101.

Salami, O. (2005). Language disorder: an introduction. Perspectives on Language and Literature. M.Olateju and L.Oyeleye. Eds. Ile-Ife: Obafemi Awolowo University Press. 37-52.

Salami L.O \& Akande, A. T. (2006). Aspects of the Grammar of the Spoken English of a Yoruba Stroke Patient. SKASE Journal of Theoretical Linguistics Vol 3. No 1 Pp 25-37.

Salami, L.O. (2008). Tongue lesion and articulation disorder in English as a second language. Papers in English and Linguistics. Vol.9 pp1-8.

Smolensky, P. (1993). Harmony, markedness, and phonological activity. Handout from Rutgers Optimality Workshops 1, New Brunswick N.J. (Available on Rutgers Optimality Archive).

Sunday A.B. (2010) The suprasegmentals of bilingual Nigerian adult aphasics. SKASE Journal of Theoretical Linguistics vol. 7, no. 2 [cit 2010-06-30] Pp. 39-66.

Wertz, R.R. (1996. Clinical description. Adult Aphasta Rehabilitation, G.L. Wallace Ed. Boston and Oxford: Butterworth-Heinemann. 39-56.

Whitaker, H.A. (1975). Linguistics and neurology Linguistics and Neighbouring Disciplines, P. Bartschand T. Vennemann. Eds. Amsterdam: North - Holland Publishing Company. 33-42.

Wingfield A. (1992). Anomia. International encyclopedia of linguistics. Vol 1.W. Bright. Ed. New York and Oxford: Oxford University Press.64-65. 